\title{
Mechanical Behavior of Fermilab-Built 1.5 m Model SSC Collider Dipoles
}

J. Strait, R. Bossert, J. Carson, K. Coulter, S. Delchamps, T. Jaffery, W. Kinney, W. Koska, S. Gourlay, M. Lamm, and M. Wake

Fermi National Accelerator Laboratory

P.O. Box 500, Batavia, Illinois 60510

R. Sims and M. Winters

SSC Laboratory

2550 Beckleymeade Ave.,Dallas, Texas 75237

September 1991

* Presented at the 12th International Conference on Magnet Technology, Leningrad, USSR, June 23-28, 1991. 


\section{Disclaimer}

This report was prepared as an account of work sponsored by an agency of the United States Government. Neither the United States Government nor any agency thereof, nor any of their employees, makes any warranty, express or implied, or assumes any legal liability or responsibility for the accuracy, completeness, or usefullness of any information, apparatus, product, or process disclosed, or represents that its use would not infringe privately owned rights. Reference herein to any specific commercial product, process, or service by trade name, trademark, manufacturer, or otherwise, does not necessarily constitute or imply its endorsement, recommendation, or favoring by the United States Government or any agency thereof. The views and opinions of authors expressed herein do not necessarily state or reflect those of the United States Government or any agency thereof. 


\title{
Mechanical Behavior of Fermilab-Built $1.5 \mathrm{~m}$ Model SSC Collider Dipoles
}

\author{
J. Strait, R. Bossert, J. Carson, K.J. Coulter, S. Delchamps, T.S. Jaffery, \\ W. Kinney, W. Koska, S. Gourlay, M.J. Lamm, M. Wake \\ Fermi National Accelerator Laboratory, P.O. Box 500, Batavia, IL 60510, USA
}

R. Sims and M. Winters

Superconducting Super Collider Laboratory, Fermilab/SSCL Magnet Project

Fermi National Accelerator Laboratory, P.O. Box 500, Batavia, II 60510, US

\begin{abstract}
Several model SSC collider dipole magnets (50 $\mathrm{mm}$ aperture, $1.5 \mathrm{~m}$ magnetic length) have been built and tested at Fermilab. These magnets are ingtrumented with strain gauges to measure atresses in the coil, the cold mass shell, and the coil end clamp assembly. Measurements are made of these quantitiea during assembly, cooldown, excitation, and warmnp. Additional mechanical measirements are made on magnet sub-assemblies during mannfacturing. Data from these measurements are presented and compared with expectations from the design calculations.
\end{abstract}

\section{INTRODUCTION}

This paper describes the mechanical behavior of several $1.5 \mathrm{~m}$ magnetic length $50 \mathrm{~mm}$ aperture SSC collider dipole magnets that have been built and tested at Fermilab, and compares the behavior with that expected from the mechanical design calculations $[1,2]$. The mechanical design of the $2 \mathrm{D}$ cross section is fully discussed in [1] and of the magnet end in [2]. The vertically split yoke contacts the collars near the horizontal mid-plane under all conditions to provide support against deflection under the IxB force. The yoke halves are clamped together by a $340 \mathrm{~mm}$ O.D., $4.95 \mathrm{~mm}$ thick stainless steel shell which is pretensioned at room temperature by weld shrinkage and whose pretension grows with cooldown. A collet assembly, consisting of a four piece G10 insulator and a stainless steel (DSA321 and 323) or aluminum (DSA324 and beyond) outer cylinder, is used to clamp the coil end. Axial force is transmitted from the coil to the shell through $38 \mathrm{~mm}$ thick end plate which is prestressed against the end clamp by four set-screws.

Measurements of important sub-assembly dimensions are made during manufacturing. Strain gauge transducers[3] measure the coil asimuthal prestress and the force between the end clamp and end plate. On some magnets strain ganges have been placed on the shell and on the end clamp.

Dats are presented from six model magnets denoted DSA321-325 and DSA327. DSA321 and 323

Manuscript received June 24, 1991. Work Supported by the U.S. Department of Energy have been fully tested and DSA324 is currently under cold test. DSA322 and 327 have been used for assembly experiments and have not been cold tested. DSA325 developed a turn-to-turn short during assembly which cleared upon disassembly and could not be repaired. DSA326 is currently being assembled and is not discussed.

\section{ASSEMBLY DATA}

The inner and outer coil prestress at important points during assembly and testing are shown in Table 1. The collars are designed to position the conductors as defined by the magnetic design [4] without the use of pole shims. This requires that the coils be molded to the correct size to achieve prestress in the desired ranges of $55-85 \mathrm{MPa}$ and 40 $70 \mathrm{MPa}$ in the inner and outer coils respectively. However, pole shims were applied to several of these magnets by adding or removing a layer of Kapton ground insulation at the pole as shown in Table I. The measured relation between coiltshim size and prestress has been nsed to determine[5] the correct

Table I

POLE SHIMS AND COIL PRESTRESS. THE UPPER (LOWER) ENTRY IN EACH PAIR CORRESPONDS TO THE INNER (OUTER) COIL.

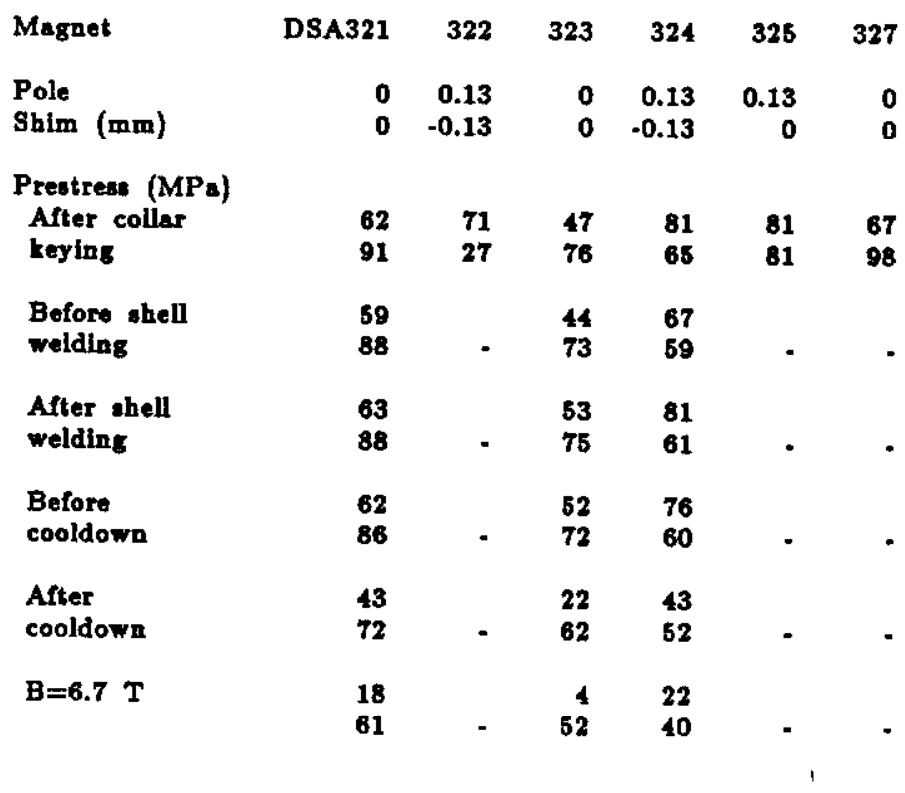


molded coil sise for the long $50 \mathrm{~mm}$ dipoles. All magnets except DSA323 have the inner prestress within the target window but the outer coil prestress tends to be systematically higher than is required. Stress relaxation occurs, especially for the higher prestress magnet DSA324, between collar keying and shell welding and between welding and cooldown.

Collar deflections with prestress are determined by comparing measured collared coil diameters with those on a collar pack assembled with keys but no coil. The relation between the vertical deflection and the inner-outer average prestress is plotted in Fig. 1 for four of the six magnets. (One was measured before adequate procedures for collar diameter measurements were instituted and is not plotted. Another was keyed by closing the collars only far enough to start the tepered keys and then driving them in with a force of $500 \mathrm{~N} / \mathrm{mm}$. This magnet cannot be compared with the others due to the possibility of additional inelastic deflections from the tapered key insertion.) The deflections are somewhat larger than predicted by finite element calculations[6] but comparable to those assumed in the design calculations[1].

Finite element calculations[6] predict a much smaller horisontal than vertical deflection with prestress. The measured horizontal radial deflections lie between -0.03 and $+0.04 \mathrm{~mm}$. This is a wider range than expected and there is no obvious relation between the deflection and prestress. Because the deflections are determined relative to one undeflected collar pack, this variation may represent the currently achieved tolerance on the assembly of the spot-welded pairs of collars[7]. This is currently under investigation.

When the shell is welded the magnet is placed in a press which compresses the yoke about the collared coil, causes the shell to conform to the yoke,

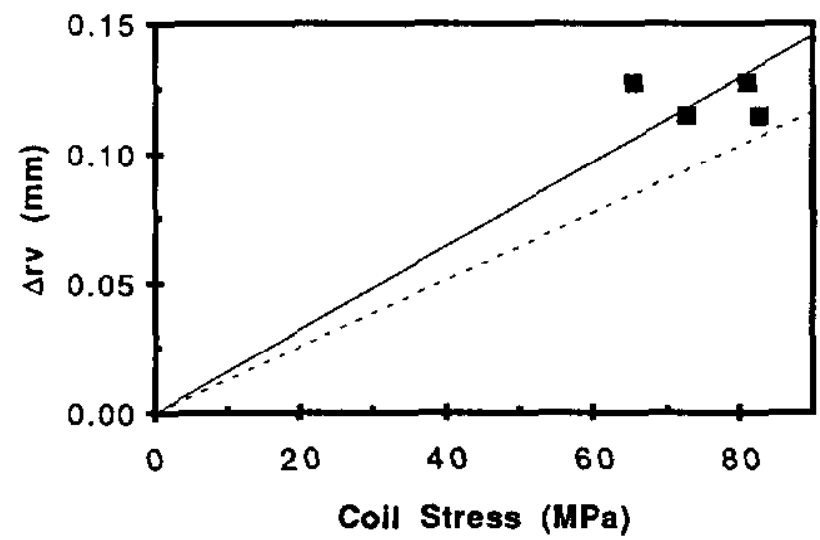

Fig. 1. Collar vertical radisl deffection va. prestress. The dashed and solid lines are the relations expected from finite element calculations and assumed in the mechanical design of the magnet respectively. and holds the entire assembly in a straight, twist-free state which is then maintained after the two shell halves are welded. Weld shrinkage causes an aximuthal stress to be developed in the shell which maintains the yoke-collar compression after the press is opened. Fig. 2 shows the DSA324 prestress as a function of yoking press load before shell welding. The dashed lines show the final prestresses after welding and removal from the press. The final prestress is the same as at a press load of $2.2 \mathrm{kN} / \mathrm{mm}$, implying an aximuthal shell tension of about $220 \mathrm{MPa}$. This is comparable to the 175$200 \mathrm{MPa}$ assumed in the mechanical design.

\section{COLD TEST DATA}

Tests at liquid helium temperature were performed in a vertical dewar in the Fermilab R\&D test facility at Lab 2. The strain gauges measuring coil stress and end force were calibrated both at $293 \mathrm{~K}$ and $4 \mathrm{~K}$ and therefore measure absolute stress at $4 \mathrm{~K}$. The zero-strain resistances of the gauges on the magnet shell and the end clamp were not calibrated at $4 \mathrm{~K}$. Therefore these gauges measure only the changes in strain at $4 \mathrm{~K}$.

Two magnets have been cold tested and a third is currently under test. The prestress losses with cooldown (Table I) are 19-33 (8-14) MPa in the inner (outer) coils, changes comparable to those in vertically-split yoke $40 \mathrm{~mm}$ model magnets and somewhat smaller than in horizontally-split models[8]. The set acrews which transfer the axial load from the coil end to the end plate are preloaded at room temperature to $3-5 \mathrm{kN}$. The load changed with cooldown by $-1 \mathrm{kN}, 0 \mathrm{kN}$, and $+1 \mathrm{kN}$ in DSA321, 323 , and 324 respectively.

The asimuthal coil stress at the pole is plotted as a function of magnet current squared (proportional

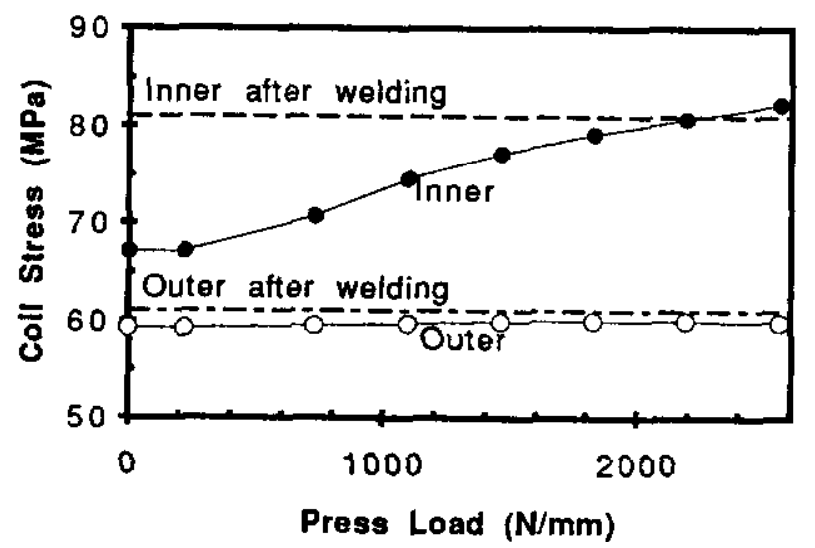

Fig. 2. DSA324 coll preatress ro. yoking press load before shell welding. The dashed lines show the finsl prestrenses after the shell wes welded and the prese was opened. 
to IxB) in Fig. 3. The SSC operating current corresponding to $20 \mathrm{TeV}$ is $6.6 \mathrm{kA}(6.7 \mathrm{~T})$ or $44 \mathrm{kA}^{2}$. The pole stress remains positive up to well above $7 \mathrm{kA}(7 \mathrm{~T})$ in DSA321 and 324 , but the DSA323 inner coil unloads near the operating current. The outer coil stress remains high through the full current range in all cases. We conclude, therefore, that the initial room temperature prestresses in the outer coils (see Table I) are considerably higher than is required, while the DSA323 inner prestress is marginally too low.

The force between the coil end clamp and the end plate is shown as a function of magnet excitation in Fig. 4. The 4-10 $\mathrm{kN}$ end-force change from 0 to the operating current is a small fraction of the total IxB force of $110 \mathrm{kN}$. Most of the axial force is, as in the $40 \mathrm{~mm}$ magnets[9], transferred to the shell via coil-collar-yoke-shell friction.

The slope with current squared was initially much smaller in DSA323 than DSA\$21. DSA323 was observed $[10]$ to quench occasionally in the return end on the down-ramp at about $4 \mathrm{kA}$. It was conjectured that the down-ramp quenching and the small end-force slope might be related and the performance could be improved by increasing the end preload. A thermal cycle was performed to allow the end set screws to be tightened to a $10 \mathrm{kN}$ load. The end force slope was then comparable to that in DSA321, but the down-ramp quenching remained. DSA323 is currently being disassembled to investigate the cause(s) of this behavior.

Strain gauges were mounted on the DSA323 shell to measure azimuthal stress at five aximuthal locations at the magnet center. Axial strain is also measured at one of the aximuthal locations. Under excitation, the IxB force in the body of the magnet induces a horizontal elliptical deflection, which can be observed by the changes in asimuthal stress in the shell: negative (compressive) near the pole $\left(90^{\circ}\right)$ and positive (extensive) near the mid-plane $\left(0^{\circ}\right)$. If the shell tension were insufficient to keep the vertical

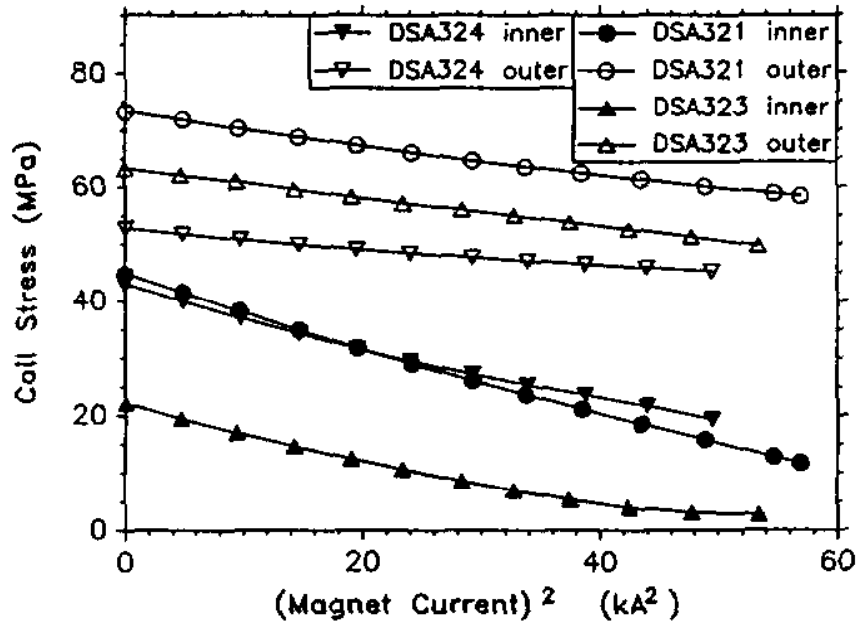

Fig. 3. Coil stress rs. magnet current squared.

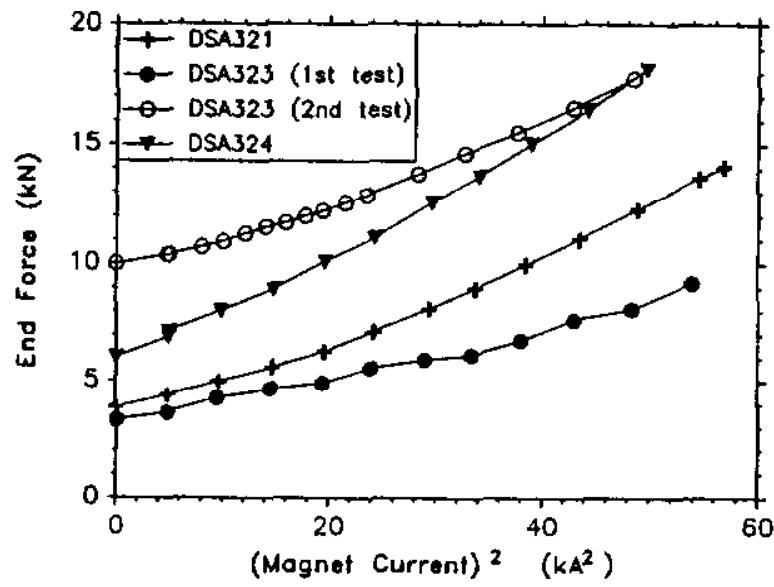

Fig. 4. End force va. current squared.

yoke parting-plane gap closed, the gauges near the pole would show a positive stress change. The axial IxB force is transferred from the coil to the shell via friction and the end loading set-screws. Therefore both axial and azimuthal stresses change with excitation and the measured strains must be corrected for the Poisson effect. This correction is done $58^{\circ}$ from the mid-plane where there are gauges measuring strain in both directions. The correction is applied at the other angular positions by assuming the axial stress to be azimuthally uniform.

The data are plotted versus current squared in Fig. 5. The pattern with aximuth is qualitatively as expected: compressive near the pole $\left(79^{\circ}\right)$ and progressively more extensive nearer the mid-plene. It is not understood why the $0^{\circ}$ stress is smaller than that at $29^{\circ}$. The stress nearest the yoke parting plane is negative over the whole range measured indicating that the yoke gap remains closed up to at least $7.7 \mathrm{kA}$ (about $7.6 \mathrm{~T}$ ).

The axial stress change to the operating current, $11 \mathrm{MPa}$, multiplied by the cross sectional ares of the shell gives an axial force of $57 \mathrm{kN}$. Presumably the remainder of the IxB force is

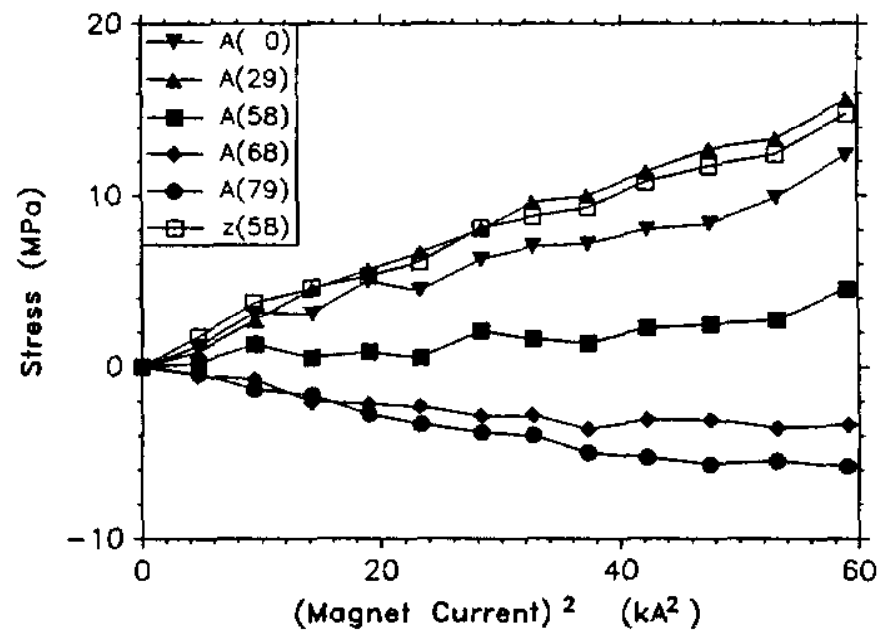

Fig. 5. Aximuthal (A) and axial (x) stress change in the DSA323 cold mase shell vo. current equared. The numbers in parentheses are the distances in degrees from the $x$-axis. 
balanced by stretching of the coil. Measurements[9] on long $40 \mathrm{~mm}$ magnets indicate that it takes about $1 \mathrm{~m}$ to fully transmit the axial force to the shell. Here the magnet center is only $0.56 \mathrm{~m}$ from the end of the yoke.

Strain gauges are also mounted on the DSA323 return end clamp outer cylinder $32 \mathrm{~mm}$ from the end of the collared portion of the coil. This is roughly centered in the $78 \mathrm{~mm}$ of coil straight section inside the end clamp. The data with excitation are plotted in Fig. 6. As in the shell, these data are consistent with horizontally elliptical deflection under excitation. If the deflection is modelled as a purely elliptical distortion of a $99 \mathrm{~mm}$ O.D, $17.5 \mathrm{~mm}$ wall cylinder the measured strains correspond to a roughly $0.05 \mathrm{~mm}$ increase in horizontal radius. This agrees within about a factor of two with finite element calculations[11].

The axial strains are much smaller than the azimuthal strains. At most a few microstrain are expected from the measured end force shown in Fig. 4. The apparent atrains most likely reflect imperfect compensation of the magneto-resistance of the gauges.

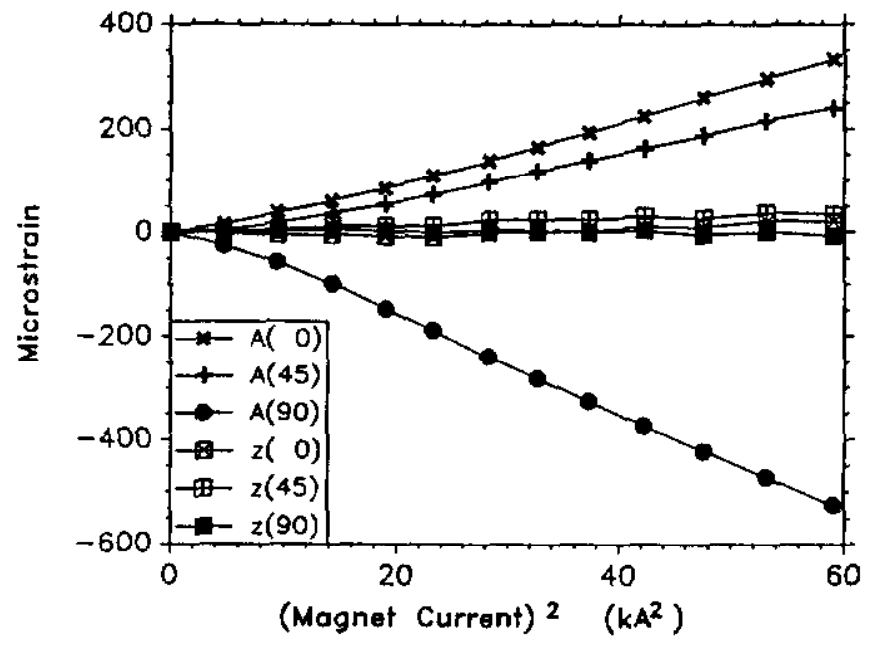

Fig. 6. Asimuthal (A) and axial (s) strain change in the return end clamp outer cylinder of DSA323 rs. current squared. The numbers in parenthesen are the dintances in degrees from the $x$-axis.

\section{CONCLUSIONS}

Three $1.5 \mathrm{~m}$ model SSC collider dipoles have been built and tested at Fermilab. Mechanical measurements from these and several other partially assembled magnets agree well with design expectations. The importent results include 1) The collar vertical deflection with prestress and the shell aximuthal tension agree quantitatively with design expectations, 2) Coil prestresses within the desired range have been achieved without pole shims, 3) Prestress loss with cooldown compares favorably with $40 \mathrm{~mm}$ models, 4) Most of the axial $\mathrm{LxB}$ force is transmitted to the shell via collar-yoke-shell friction and not by compressive loading of the coil end, 5) The yoke parting plane gap remains closed to well above the operating point, and 6) end clamp deflections are $\$ 0.05 \mathrm{~mm}$ under excitation. Issues still to be resolved include 1) The larger than expected spread in horizontal radius of the collared coil, 2) The significant difference in end-force slope with excitation among the magnets tested, and 3) The possibility that long magnets may behave differently in some respects, particularly in their axial mechanics.

\section{ACKNOWLEDGMENTS}

We would like to thank the staffs of the Fermilab Superconducting Magnet Production group and of the Superconducting Magnet R\&D Facility at Lab 2 whose dedication and care made this work possible.

\section{REFERENCES}

[1] J. Strait et al., "Mechenical deaign of the 2D crosssection of the SSC collider dipole magnet," submitted to the 1991 IEEE Particle Accelerator Conference, San Franciuco, CA, May 6-9, 1991.

[2] S. Delchamp: et al., "SSC collider dipole magnet end mechanical deaign," submitted to the 1991 IEEE Particle Accelerator Conference, San Franctsco, CA, May 6-9, 1991.

[3] C.L. Goodseit et al., "Meanurement of internsl torce: in superconducting accelerator magnet, with strain gauge transducen," IIEE Trens. Magn. vol. 25, pp. 1463-1468, March 1989.

[4] R.C. Gupte et al., "SSC $50 \mathrm{~mm}$ dipole crons section," submitted to the 3rd International Industrial Symposium on Super Collider, Atlante, GA, March 13-15, 1991.

(5) M. Wake et al., "Teste of 1.5 meter model $50 \mathrm{~mm}$ SSC collider dipoles at Fermilab," submitted to the IEEE Particle Accelerator Conference, San Francisco, CA, May 6-9, 1991.

[6] J. Kerby, "Mechanical Analysie of the Vertically Split Yoke $50 \mathrm{~mm}$ SSC Dipole," Fermilab Technical Support Section internal note TS-SSC 91-001, Dec. 30, 1990.

[7] A. Derred ot al., "Status of 4-cm aperture, 17-m-long SSC dipole magnet R\&D program at BNL part I: magnet assembly," submitted to the 3rd International Induetrial Symposium on the Supercollider, Atlanta, GA, March 13.15, 1991.

[8] W. Koska et al., "Tests of $40 \mathrm{~mm}$ SSC dipole model magnete with vertically split yokes," submitted to the IEEE Particle Accelerator Conference, San Francisco, CA, May 6*9, 1991.

[9] J. Strait et al., "Teats of full acale SSC R\&D dipole magnets," IEEE Trane. Magn. vol. 25, pp. 1455-1458, March 1989.

[10] M. Wake, al., "Quench behavior of 1.5 m model SSC collider dipole magnete at Fermilab," submitted to the 12th Internstional Conference on Magnet Technology, Leningrad, USSR, June 24-28, 1991.

[11] J. Kerby, "Finite element analysis of end collet mechanism," TS-SSC 90-085, Nov. 6, 1990. 